\title{
Time to Separate the Men From the Beasts: Symbolic Anticipation as the Typically Human Subjective Dimension
}

\author{
Dieter De Grave*
}

*St. Norbertus-huis, Stationsstaat 22c, 2570 Duffel, Belgium

\begin{abstract}
In this paper it is argued that the dividing line that runs between the human psyche as opposed to any other complex system is made up by symbolic anticipation. The functionality of the human mind as an anticipatory system is entirely caught up in the crucial role that finiteness, shortage or lack plays for human beings. Anticipation for us is the way by which this negative finiteness or lack is translated into a positive longing, want or desire. We take a look at the three dimensional view of Jacques Lacan regarding these matters in a sophistical example and we illustrate how anticipation as a Symbolic phenomenon is distinct from the Imaginary or the Real register. As Lacan points out anticipation creates a symbolic social link which binds two or more interacting humans together in an anticipatory relationship. Beliefs, expectations and convictions are the typically human social links which ground human interaction and set it apart from other forms of social interaction we can observe in other complex biological entities.
\end{abstract}

Keywords: Complex systems, Psychoanalysis, RSI, Social Link, Translation.

\section{BEGINNING AT THE END IS WHAT ANTICIPATION IS ALL ABOUT}

Let's start at the end, so that there can be no mistake about our pretences. What is the crucial difference between human and all other forms of anticipation? It is the symbolic way in which this form of anticipation comes about in human beings that makes up all the difference. In other complex systems, anticipation comes about on a real (arousal) or on an imaginary (representational) level. Humans experience these two forms of anticipation as well, but the symbolic one is strictly and exclusively human. Symbolic anticipation is what makes us what we are and what sets us apart from all other complex systems. (Human) identity and (symbolic) anticipation are interwoven concepts [1].

What do I mean when I write symbolic in relation to anticipation? As we will come to see in this presentation, the symbol and its function are entirely caught up in the way something is not instantly representable in a logical systematory interpretational field but there is a great need to do this instantly because the weight of the logical representation is far too important for the system that is trying to make sense of what is going on.

The subject has to act to resolve a problem, but (s)he doesn't know on what grounds. In other words, you need to anticipate a solution to a self-relevant problem, a solution which seems unsolvable at first sight based on the premisses you have at that time. As Kant writes in his Critique of Pure Reason, the anticipation starts a priori as that which is intuitively anticipated in the perception and this is an sich an impossible endeavour. You cannot sense what you will perceive a priori, you can only sense what you perceive right here and now. Yet that is what happens in anticipation, which leaves us with a paradox [2].

A symbol is always something that is and stays ambiguous for it tries to attain a certain unambiguity in the signifying process, while at the same time it creates more ambiguity. This is because the signifying relation between signifier and signified or even between two signifiers is not at all stable [3]. The definition of Lacan for a signifier, the epithome of a symbol, is that it is something which represents a subject for another signifier [4]. So the relationship between signifiers is always mediated by a subject that is caught up in this signifying process. In a scheme: 


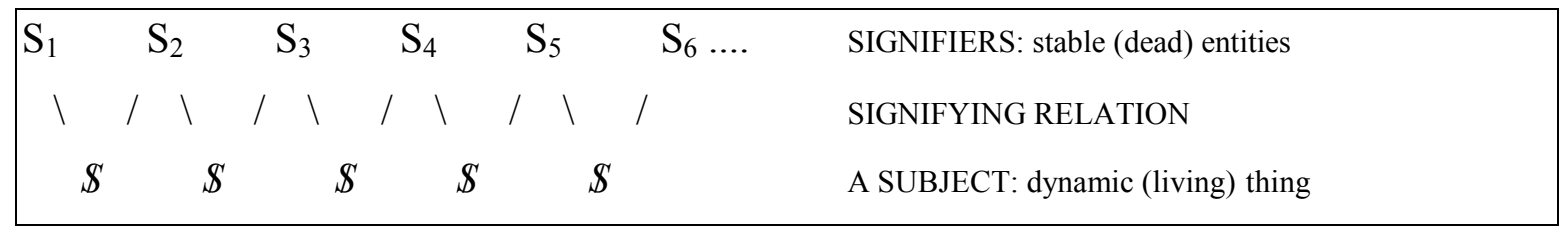

FIGURE 1. The signifier chain

The only way out of the chaotic mess of dead signifiers and a living subject is the reference of one signifier to another signifier through a subject over time, to a certain temporal subjective context. The role of the subject is crucial, for it is (s)he who makes the reference possible. Subjectivity and symbols are interdependent: without one there cannot be the other. For the symbol the subject is its context and for the subject the signifiers are his context. For this reason a symbol as opposed to an image (imaginary) or a feeling (real) never makes sense as an isolated entity of the dual relation between one feeling or image in relation to one subject; a symbol always needs a subject and a temporal (con)text to make it more or hopefully less ambiguous.

In short, a symbol symbolizes nothing except by way of its temporal subjective context, which makes up the chain of signifiers. The relation between these signifiers in the chain is always mediated by a subject. As isolated entities they mean nothing. This contextual relation takes away some of the emptiness and ambiguity embedded in the symbol by way of relevance for the system itself (the subject) and for the environment surrounding the system (the signifiers and the non-signified context). The symbol can only make sense here and now in the way it can be embedded in a temporal context which is then and there. The present of a symbol is entirely caught up in its use in the past state of the subject and its reference to a possible future state of the subject.

This is where anticipation kicks in. There is a crucial link between the symbol, ambiguity and subjective anticipation. For if a symbol really had nothing to symbolize ever, it would remain totally chaotic and ambiguous and would be of no importance at all. We could leave the field of the symbols completely aside from a scientific point of view and restrict ourselves to feelings and imagery. This is fortunately not the case, the symbol may be ambiguous at present (taken as an isolated event), it always refers to a anticipated subjective context in which the symbol will receive a meaning which will not be unclear at all, at least to one subject. Symbols have the potential for being clear and this potential is completely dependent upon its reference to a disambiguating context which must follow and this context is what is anticipated: a future meaning it unwittingly already has in the present.

In other words, for symbols to make sense, they have to be placed in a temporal context which is anticipated in the creation of the symbol itself by the subject creating them. A subject needs to symbolize, and symbols need to be subjectified, it is literally a matter of life and death [5]. If symbols are no longer sensically uttered, they lose their meaning, and if a subject stops symbolizing, (s)he loses their capacity to make sense of the past and future. In the anticipatory symbolic process, you are able to give up the immediacy of sensical information in the present for the promise of future or past sense. As we will see, this future sense is always based on human social symbolic interaction.

Some readers might be wondering what all the fuss is about. What is the relevance of all this material? I will give three relevant reasons why attention to symbolic anticipation is necessarily an object of future scientific thought which takes subjectivity into account.

The first is a theoretical one, non-reductionism. As most will have guessed by now, my own theoretical framework is that of Lacanian psychoanalysis on the one hand, and of complexity theory on the other. The choice for this framework comes forth from an abhorrence of reductionism. Whilst reductionism is of great use for us in everyday life, we should never forget that reducing a problem to its bits and pieces will never allow us to gain a greater insight into what is really going on, namely the interactions between these bits and pieces on a certain scale of organisation. Symbolic anticipation, when reduced to its nuts and bolts in the present, is essentially nothing, nothing sensical anyway. To understand anticipation, we have to take a certain subjective distance from our studied object to study the interactional processes in their greater context on different levels of organisation. Don't be too hasty to conclude something on basis of what you see, give it some time.

The second is a scientific one, evolutionary psychology. As you all know, evolutionary psychology is very much in vogue in the scientific community nowadays as an explanatory context in which to place all psychological phenomena. The evolutionary psychologists'framework may be of some value to us, but we should be very much aware of the dangers it entails. For the neo-darwinist evolutionary view is one of continuity. "There can be no doubt that the difference between the mind of the lowest man and that of the highest animal is immense. Nevertheless the difference, great as it is, certainly is one of degree and not of kind." [6] The neo-darwinists follow Darwin on this 
point and that is a very dangerous normative enterprise. This view can make you blind for the specific interactional patterns which set us apart from all other creatures, it can also make our closest relatives like the bonobos, look like complete maladapted organisms. The thought of continuity runs against every intuition you can have regarding our status in the world and in the evolution of our specific species [7]. There is a gap between ourselves and all other primates and the search for a missing link is nonsensical. We are not some species of smart chimps, we are a new species alltogether [8]. To understand our otherness is to understand our very specific way of handling anticipation, among other things like language and culture. These things set us apart from the other organisms and to understand ourselves, we should look at ourselves to see the differences with other animals, not just at other animals to see how better off we are. What sets us apart is our difference, not the likeness itself plus or minus some special intrinsic quality as others might think [9].

The third is a clinical one, that of psychological relevance. Why study symbolic anticipation? In my own work with schizophrenics, I am continuously reminded that most of these patients fail miserably when it comes to making realistic expectations about themselves or others. This nevertheless does not stop them from anticipating events and feelings which are in our view clearly delusional. Most of the time they ascertain that they expect things they know are delusional, but on the other hand most of their behaviour and thoughts seem to continue to anticipate the delusional idea. Anticipation and realism seem to function on a different level. To me, it still is a great mystery how these patients can continue to model their thought and behaviour patterns in an anticipatory way towards a delusional idea which they know is wrong. How can you continue to anticipate error or delusion? I will not work this point out in more detail, but it is too important not to mention in anticipation of future work on this subject.

\section{LACAN AND SYMBOLIC ANTICIPATION/ LOGICAL TIMES AS A SOPHISM}

In 1945 Jacques Lacan published a peculiar text of just 17 pages long "Le temps logique et l'assertion de certitude anticipée. Un nouveau sophisme" [10]. In this text Lacan tries to explain how a human being comes to find his own identity in relation to the behaviour of others. For this enterprise, he uses a riddle, which I will try to explain in some detail under the next heading. All references to the riddle come from this text, unless otherwise specified.

Before we go in to the riddle itself, we must first stress that this text and the example in it are not very well studied, nor understood. Very few Lacanians give it the attention it deserves, mainly because the problem, as Lacan explains it in his own dense inimitable style, is very hard to follow $[11,12,13,14]$. Secondly, the conclusions that can be drawn from this text are far from clear and can only be guessed at by the one deciphering the text.

The importance for understanding it however, is tremendous. A lot of Lacan's other theorems and paradigms (like the demarcation Real-Imaginary-Symbolic, anxiety, phantasm, narcissism, etc.) are shed in a whole different light if you take this text into account. This is nonetheless not the main reason for taking up this text and the example of the three prisoners in the context of this presentation.

The main reason is to point out in the text the main form of human anticipation in regards to identity. Humans find their own identity in relation to other humans in the way they interact in a certain way. The way in which this interaction comes about is clearly anticipatory and can only be anticipatory, as I will hopefully be able to point out. Humans as self-aware creatures can only enter the typically human way of interaction with others by way of symbolic anticipation.

\subsection{The Riddle of the Three Prisoners}

Let us take up the riddle itself as best possible. It goes as follows. A prison director selects three prisoners $(\mathrm{A}, \mathrm{B}, \mathrm{C})$ from his jail and says that he has to release one of them for undisclosed reasons. To decide which one will be released, he has thought up a riddle. He has 5 discs in his possession, 2 blacks $(\bullet \bullet)$ and 3 whites (०००). The prisoners are aware of this. He will fasten one of these discs on each of the three prisoners, so that they cannot see the color of the disc on their own back, only the discs of the other two. Now, the director will release the one who can come to him first and say what the color of his disc is, based on logical (not probalistic) grounds from what he has seen from the others. He then fastens 3 white discs on the prisoners. The solution to this problem is that each of the prisoners goes to the director at the same time and declares himself white. How can this come to be? Let's try to explain. 


\subsection{The (not so) Perfect Solution}

First of all, it is important to mention that this is a pure thought experiment. The prisoners are fictional characters which are equal in every way imaginable (wanting, intelligence, looks, etc.) But they are clearly human, for they are driven by a common goal, to solve the riddle so they will be set free. They know that they have to solve the riddle for their own good. So, solving the riddle is a self-relevant enterprise for each of the prisoners and to find the solution, they are dependent on the actions of the others to obtain a reward for themselves, not for the whole.

Secondly, the problem does not have a clear logical solution if seen from the viewpoint of the prisoners. From the perspective of the prisoners, the logic is not clear-cut. Let us look at what each prisoner sees (figure 2), what he would like to see (figure 3) and what he does see and do in relation to the others (figures 4, 5, 6 and 7). To make things more easy, let us take the perspective of A. Note that this choice is purely arbitrary, we could just as easily select $\mathrm{B}$ or $\mathrm{C}$, because the three prisoners are identical in their thinking process. Now what is A's real situation?

\section{B}

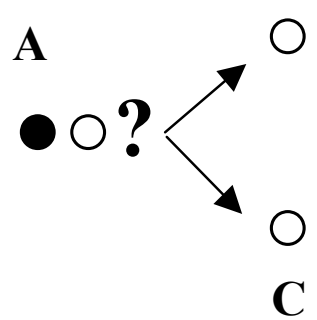

FIGURE 2. The real situation for prisoner A

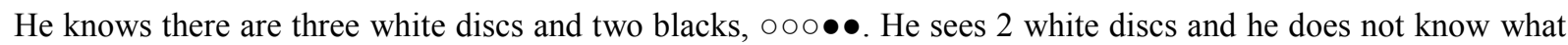
color of disc he has.

If the other two were black, the answer would be that he has a white disc for sure, and that is what every prisoner would wish for, a clear-cut solution to the problem. Let us now look at the imagined perfect situation for A

\section{B}

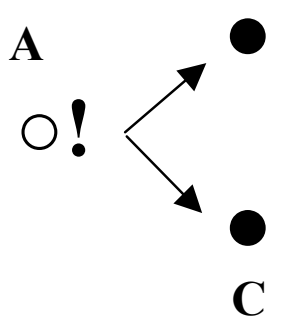

FIGURE 3. The imagined perfect situation for prisoner A.

How to solve this problem? Here follows what Lacan calls the perfect solution: Suppose I am black. If I am black, then B can suppose that he is also black, but then $\mathrm{C}$ would see two blacks and know that he is white and leave. C doesn't leave, so B should know that he is white, given that I am black. B doesn't leave, so I must be white, so I can leave.

Let's pull this solution apart to make it more clear. 
B

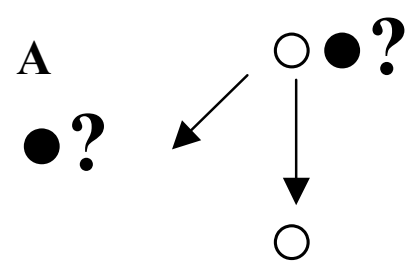

C

FIGURE 4. If A were black, B could also imagine himself black

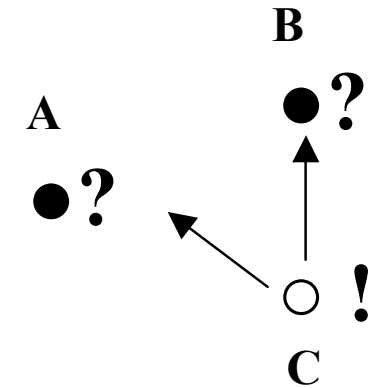

FIGURE 5. If B were black and A too, then $\mathrm{C}$ would know he is white for sure and leave
B

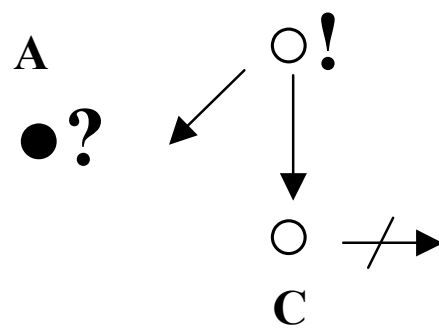

FIGURE 6. C doesn't leave,

so $\mathrm{B}$ should know he is white and leave
B

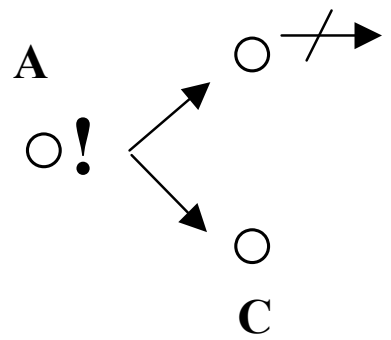

FIGURE 7. B doesn't leave, so he doesn't see A as black, so A concludes that he is white

Because nobody moves, all of the prisoners know that they are white and move towards the director at the same time. Here it becomes clear that the riddle is a sophistic one, because it has no clear non-temporal logical solution. For, when all prisoners move at the same time, it is quite possible that one of them is actually black. This is because not one of the prisoners can know if the other prisoners were not moving based upon what they see or imagine but because they were just waiting to see what the others do. How long do you have to wait to know that the others are waiting too? Let me remind you that if one of the prisoners, say B, actually sees one black and one white, he is also dependent on the inertia of an other, namely $\mathrm{C}$, to come to his conclusion (Figure 5 and 6 ). And it might be that $\mathrm{C}$ is waiting to move just long enough for the others to figure out their own identity. C doesn't have to wait, but maybe he is doing just that, waiting for no reason at all.

So it is possible that there is at least one black disc in the game when everybody begins to move. The assumption of being white is based on the inertia of the others and when they begin to move the solution is not so certain anymore. Everybody halts because they are in doubt about their own identity. So, the argument begins anew. Nobody moves, so I must be white, everybody moves, so the solution becomes unclear again. Is this a regressus ad infinitum, a variation on the turtle of Zeno? No, two halts will suffice to be absolutely sure that all three are white. It is here that the role of anticipation and temporal subjectivity will become clear.

\subsection{The two Stops on the Ladder of Knowledge}

From a certain time-perspective, something peculiar happens. In the first instance (the perfect solution) everybody in the group is thinking about the color of his own disc and everybody makes the same reasoning to come to the same conclusion based on the inertia of the others. But when everybody moves, nobody is certain about his conclusion anymore. So they stop. What does this first halt teach the prisoners? 
The first lesson from the first stop is that the two black disc possibility is not an option. The prisoners knew this already from observation and now it is confirmed by the halt of the others. This is because, in the case of the $\bullet \bullet \circ$ option, the one with the white disc (prisoner C) would be absolutely sure of his whiteness and would not halt as the others do. The other two halt because they follow Step 2, they imagine the possibility to be $\circ \bullet \bullet$, where they themselves are $\bullet$ and the other one who is hesitating is $\bullet$ too. The observation is that everybody halts, so no two black discs are in the game. We knew this already, but now it is confirmed in the first halt.

Everybody thinks again, starts to move again at the same time and everybody halts at the same time again. What is the difference between this second halt and the first? The answer is that in the first halt information was gained for the thinking model about the disc-identity of each individual. The perfect solution as Lacan called it, is partly based on the assumption that there could be two black discs in the game. The first halt ruled this illogical possibility out. Now what does this information tell us?

Before the second halt, the possibility of just one black disc remained open, $\circ \circ \bullet$. If $\mathrm{A}$ is a black disc, then B and $\mathrm{C}$ absolutely know they are white discs, because the possibility of being black themselves in view of one black disc was ruled out by the first halt. $\mathrm{B}$ and $\mathrm{C}$ could continue their journey towards the director without halting a second time.

The truth is however that everybody halts a second time. So, in the second halt information is gained once again because the one black disc option, $\circ \circ \bullet$, is ruled out too. This information is useful for the individual, because it says something definite about his identity. If no one sees a black disc, then everybody must be white, so every individual knows that he himself is definitely white, so every prisoner has solved the riddle at the same time. The correct answer is $০ \circ ০$, which is now the only available option based on the two halts. The solution is that there is no solution for anyone in particular and this is the solution for everybody.

This is a very unfortunate conclusion for our prisoners, because in the end no one is able to win the game because they know the answer simultaneously, so no one can be released. They lose the game by solving the riddle. Hence the sophism.

\section{SYMBOLIC ANTICIPATION AS A SOCIAL INTERACTIONAL SYSTEM OF SHARED BELIEFS: IDENTITY}

Where is the anticipation in this riddle and why is it symbolic and not just merely real and/or imaginary? The anticipation lies in the frustration of the first instant of seeing two white discs. Nothing certain can be extrapolated from this view of $\circ \circ$, only the sight of two black discs would immediately lead to a certain conclusion, being white, $\bullet \bullet ?, \circ$ !. So, because the prisoners do not see what could solve the problem, they start the process of building thinking models based upon what the others might see. If they could solve the problem immediately on their own, they would not need the imagined perspective and the perceived movement of the others. The prisoners start their thinking in anticipation of certainty about their own identity, a certainty they can never be sure of from the start. It is in the temporal context that the anticipation of certainty is fulfilled.

They move from their own viewpoint to the imagined viewpoint of the others. I cannot see my own identity, but the others can. In the imagination of the perspective of the other they look for the information they need to be freed. How and why is this possible? They know that only one view lends itself to an immediate and absolute conclusion, seeing $\bullet \bullet$. This not being the case, the prisoners anticipate that a conclusion can be reached over time if they move their mind's eye from their own viewing point to that of the others. Do they see $\bullet \bullet$ ? Because the immediate solution is not there, from their own perspective viewpoint, they anticipate it in the perspective of the others. They anticipate that a certainty about their own state can be extrapolated from the movement of the others in combination with a thought experiment about the identity of self. If they do not, they will be stuck forever staring at the two white discs in front of them.

In their anticipation of a possible solution, the prisoners do more than just search for a solution. Their search is based upon the absence of information from their own viewpoint, namely their own identity and they know that the others are struggling with just the same problem. But they have an angle on him, as he has an angle on them. They see his identity directly, although they do not see their own identity. So every prisoner knows more and less about the whole situation than the others. In other words, the prisoners are joined in a social bond based on their lack and their surplus of information. They want something from each other -the confirmation of their identity- and they have something to give - the confirmation of the others' identities.

So they extrapolate on what the others might see, but not one of the prisoners can be sure of what the others see. They imagine themselves being black, and look what this route leads them to. To be able to simply do this -imagine 
yourself being something or other- requires an enormous amount of insight in the perspective of others and a tolerance towards not knowing something in expectation of a solution. But it doesn't end there.

When the prisoner places himself in the perspective of the other and imagines himself black, he then takes a crucial thinking step which is not based on any possible observation or logic, namely the perspective of there being two black discs from the viewpoint of another. Because every prisoner sees two white discs, the presence of two blacks is simply not an option, yet it is a crucial step in the thinking process.

When you look at the riddle and the perfect solution, you see that the lack of information is transferred to the other, namely in figure 4. B should not imagine himself being black if A isn't black, it simply wouldn't make sense to do so. Only if A is black, a solution can be found because only then, on the basis of one disc in view being black can one of the options, $\bullet \bullet$, be ruled out in the movement process. And, moreover, only because B doesn't know his own identity can this route be taken. From the viewpoint of A, it is clear that B cannot be black, but B doesn't know this. If B imagines himself black, he is wrong from the viewpoint of A. But A needs to forget what he sees, because B doesn't know what A knows, that B is white and that he couldn't possibly be black. You can check it if you want, you cannot solve the riddle if you do not explicitly rule out the possibility of two black discs, you yourself being black and one of the other whites making the same mistaken judgment. You need the impossible absolute option of two black discs. Only this option leads to an absolutely certain conclusion. This means that in order to reduce options, you have to create more options, even impossible ones. To move forward, you have to move back, distrust what you know from observation.

Why move back in the thinking process? Because the solution is anticipated, based on the absence of immediate certainty and the possibility of certainty over time about identity. They see the others, they don't see themselves. They can move their Mind's eye from their own perspective to that of the others and "repress" that they have a certain knowledge the others do not have, namely their state of identity. It is the absence, the lack that is the crucial factor and it is this, which sets the symbolic level apart from all other fields of interaction. Let us go into more detail here.

\section{REAL, IMAGINARY AND SYMBOLIC ANTICIPATION}

In the sophism, what is the real anticipation? It is freedom, the drive to be set free [15]. Each of the prisoners lacks freedom and wants to be freed, so they enter the game in order to satisfy their need to be freed. They don't have the freedom, but the anticipation of the fulfillment of this want or desire is the motivator behind the game. This reward says nothing about the solution of the problem, it only states that the actions of the prisoners in the game are motivated in anticipation of a real change in situation, to become free. The real anticipation has no direct role to play in sorting out the logic behind the riddle.

What is the imaginary anticipation? [16] It is representing the real situation in the mind's eye, o०, and relating it to the representative solution for the problem at hand, $\bullet \bullet$. To solve the game without social interaction, you just have to see a certain situation, namely two black discs. What is the lack, which motivates the imaginary anticipation? This lack is double: one the one hand one cannot see his own identity and on the other hand one doesn't see the image that could lead directly to the solution of the identity question. Clearly, in the riddle, there is a difference between what the subject sees (Figure 2) and what he wants to see (Figure 3) and there is no middle ground to mediate between these two images. This middle ground is the symbolic level, as it is based on the absence, not on the presence of useful information.

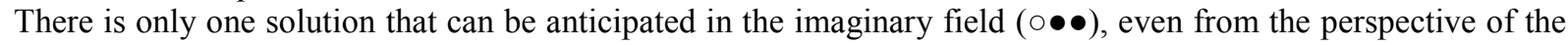
others. Even with the $\bullet \circ$ option in view, this could lead to a logical imaginary solution for someone else, because then it could be that the looking subject is the seen object $\bullet$, so one of the other prisoners could become positively sure about his identity, because he sees $\bullet \bullet$ and concludes he is $\odot$. This sets the door open for imaginary rivalry -the other might see the solution even if I can't. This rivalry is the inspiration to move from the imaginary to the symbolic level. I will not work out this point in this paper.

The imaginary relation is always one of duality, between a subject and an object, between someone who sees and something which is seen [17,18]. Imaginary anticipation is always rule based and positive. It always involves relating what is seen to the state of the subject in question.

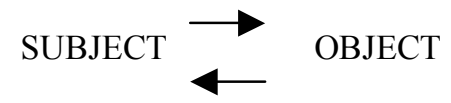


This dual relation is clear-cut and objectifiable: if you see this $\bullet \bullet$, then that $\bigcirc$ will be the case for you. The information gained from the image has to be unambiguous. Ambiguous images can simply not be computed into an imaginary logic. The observed object or phenomenon should lead to a strict conclusion about its relevance for the subject. Ambiguity is not imaginary tolerable and should be worked away by making the view of the object more objectifiable. The imaginary solution $(\circ \bullet \bullet)$ is necessary to be absolutely certain about the subject's identity and hence to be set free. But this solution is not sufficient because it collides with the real view (००). The imaginary anticipation based on what is seen, could go on forever without leading to a solution. All prisoners would be frozen in time searching for a solution based on the image they see.

So, what then is symbolic anticipation? It is based upon the clash between continuous absence of and the ongoing need for a clear-cut solution for the looking subject on the one hand and the possibility for interpretation and translation of what goes on between the subjects on a social level, on the other. The social interactions are translated into a self-relevant logic for the subject. The prerequisite for this possible interaction and translation is the lack of immediate certainty about the solution. Only if the subjects don't see $\bullet \bullet$ can the symbolic interaction start. Otherwise, the imaginary level would suffice for one of them.

In order to solve this situation, we need information from the other subjects to come to a certain solution about our own situation. What exactly does it mean to see $\circ \circ$ ? It means nothing except in relation to the others and what they see. Do they see the same thing I do, ००? Do they see $\bullet \bullet$ ? What is the difference between me and the others? What can be known about this difference by me? In short, what do the others tell me about me? The movement or lack thereof by the others is translated by the subject to interpret what they might see and what they might extrapolate on this perception.

The symbolic interactions are based on the actions and hesitations of the others. These prove in mere 4 thinking steps, repeated over two stops that they are in the same predicament as the subject who is interpreting the signs. The actions are the symbolic anticipations because they are based on conclusions that cannot be assured at the present moment. When the prisoner A starts to move on the basis that the others don't move, he anticipates something which will only become sure of after two stops. He doesn't know that he is going to make two stops or that the others will make them, but still he acts upon his knowledge from his thought experiment confirmed by the non-movement of the others. When everybody begins to move at the same time, the conclusion is put into question. The anticipated certainty was premature.

Only after two stops can it become absolutely clear that every prisoner can decipher his identity. The conclusion is that they are all the same, bound in fate so to speak. Starting from the viewpoint of the others as possibly different, they all come to the conclusion that there is no difference. The use of the imagined difference was necessary to interpret the actions and hesitations of the others and in this interactional context, the movement of the subject becomes clear. Symbolic anticipation always needs a context, which evolves over time and this context is based upon a lack of clear-cut information.

What the symbolic anticipation teaches us is that ambiguity is not an obstacle, but a part of the solution. Only because there can be ambiguity, can there be certainty in the interactional process. Symbolic anticipation is based upon uncertainty, which goes away over time if certain constraintive interactional rules are followed. Symbolic anticipation is based on absence, not on presence, because only on the locus of the lack can the interactional disambiguating context be brought to the fore. In real anticipation ambiguity creates discomfort and tension, in imaginary anticipation ambiguity poses an insurmountable obstacle, in symbolic anticipation it is a necessary part of the process.

\section{IN CONCLUSION: THE END IS WHERE WE START FROM}

We are back where we started from without having said anything which is directly useful for scientific research or even scientific thought. I have tried to point out the difference between real, imaginary and symbolic anticipation, but that is all. In this conclusion I will mention some possible places where this theory about symbolic anticipation might be scientifically useful.

Let us start with the possible theoretical implications. symbolic anticipation is the bane against reductionism. First of all, to understand the symbolic anticipatory process, you have to use a theory that can cope with or even compute duration and change within a system imbedded in a certain context.

Second of all, you need a theory that can cope with subjectivity and subjectivity is based upon the absence of absolute presence. In essence a subject is something which is lacking is some way and which tries to cope with this lack by translating it into something useful. To understand symbolic anticipation, you need a non-reductionist theory 
of complexity, where nonsense can become sense over time. The sophism makes this absolutely clear. If you reduce the solutions to just one clear-cut option, you will remain stuck forever.

Third of all, symbolic anticipation is always embedded in a social context of interacting individuals. Only in the interaction can something be understood about the state of the individual. An isolated individual is an individual who is seriously handicapped in finding a solution to his problems. Only a sociological theory of interactions can understand the way in which humans come to their interactive identities.

Next, the possible scientific implications. First, let me point out that only humans are capable of exploring the difference between themselves and the others based on a symbolic anticipatory logic. This is because in symbolic anticipation a crucial step is made when the subject realizes that the absence of a clear solution is the solution to the problem in relation to a specific interactional context. The acceptance of the lack as a workable theorem (less is more) is something that other complex systems simply cannot deal with in the same social way humans can. Humans are paradoxical creatures and so they can cope with paradoxes like the sophism we spoke about because they share the paradox.

This brings us to the second scientific implication: animal research and the idea of continuity [19] One of the ways to research the likeness of animals and humans in forming their identity is the mirror test [20,21]. Some mammals recognize themselves in the mirror, as humans do. Well, is this really the case? Our sophism points out the difference. When an animal recognizes himself in the mirror, it does just that: it finds a correspondence between his own bodily state and the image he sees. But this is mere recognition, whereas in humans the recognition is anticipatory to a social interactional level. In the mirror stage a human baby not only recognizes himself in a dual relation with the mirror, he also becomes aware that he can be an image for someone else, even for himself [22]. Other than with the animal in front of the mirror, the baby anticipates that he will become more than just this image, based on this image. His identity will not just be this interaction with a mirror but his interaction with other human beings. Humans link their social interaction to their relation with the mirror image, where in animals these two interactional patterns will remain isolated. This leads to an entirely different social identity theory, one based on narcissism: how do the actions of the other mirror me as a human being. Humans have hundreds of different identities which changes a bit with every social interaction. A female human can be a mother, a psychologist, a lover, an enemy, a distant relative, etc. She can even be male, a goddess, a cartoon character or a chinchilla for that matter. Dependent on the social interactional patterns, we can become virtually anything, because there is no stable or rigid persona. As long as we can imagine what it would be like to be this or that person, animal or object, we can take up part of its identity. Animals are most of the time just what they are, one stable persona within a certain more or less stable social hierarchy. This does not mean that these identities cannot shift over time or that they are not subject to change. I simply want to stress that in animals the role and function of identity within a social bond is more or less fixed for a lengthy period of time. Here lies the crucial difference between animals and humans, we lack a rigidly stable identity and this is our strength instead of our weakness. We are not some sort of idiotic or psychotic chimps, we are a new species altogether. We anticipate the becoming of ourselves although we never reach that point. Until we die, we are always becoming someone or something in anticipation of our stable identity, a virtual point we never reach. Of course, a lot more scientific investigation on this point is necessary to support this thesis.

And last but certainly not least, the relevance for neuro-psychoanalytical research. I agree with Ramachandran that the discovery of the mirror neurons will probably be for psychology, what the discovery of genes were for biology [23]. Mirror neurons even offer an alternative explanation for what happens in our sophism. We copy internally what we see the others do, so that we can feel or anticipate why this action makes sense [24]. To just copy the actions and hesitations of the others is to solve the problem. But, and this is crucial, to be able to copy is not to understand, because it does not take symbolic anticipation into account. It is not because you can feel what you see the other doing by way of your mirror neurons, that you understand, let alone act in anticipation. Mirror neurons may hold the key to unlocking the mystery of the interactional brain, but only in the right neurophysiological, psychological and social context. To reduce every question of identity and recognition to mirror neurons is unwise.

Our sophism points out that the question of identity and imitation is broader than the mirroring effect of the action of the subject or the others. The most important factor in all these matters is the translation of the lack into something functional. The solution is that there is no solution. Only when we can become acquainted with the way in which our mirror neurons can interpret the absence of actions, can we come to a workable synthesis of the psychoanalytical and neurological approach to human identity. What can not be mirrored and how does this relate to our identification processes as human beings? This could be a question for further neuropsychoanalytical investigation, both theoretically and experimentally. 


\section{REFERENCES}

1. Nadin, M., Mind-Anticipation and Chaos, Belser Press, Stuttgart, 1991.

2. Kant, I. Critique of Pure Reason, Everyman London, 1998 [1781].

3. Deacon, T.W., The Symbolic Species, Norton and Company, New York, 1997.

4. Lacan, J., Le Séminaire, Livre XI, Les quatre concepts fondamentaux de la psychanalyse. texte établi par J.-A. Miller, du Seuil, Paris, 1973 [1964].

5. Lacan, J., Le Séminaire, Livre XI, Les quatre concepts fondamentaux de la psychanalyse. texte établi par J.-A. Miller, du Seuil, Paris, 1973 [1964].

6. Darwin, C., The Descent of Man, Modern Library, New York, 1982 [1871].

7. Povinelli, D.J. and Bering, J.M., "The Mentality of Apes Revisited", Current Directions in Psychological Science, Vol.11, nr.4, 2002, pp.115-119.

8. Deacon, T.W., The Symbolic Species, Norton and Company, New York, 1997.

9. Savage-Rumbaugh, E.S., Ape Language: From Conditioned Response to Symbol, Columbia University Press, New York, 1986.

10. Lacan, J., "Le temps logique et l'assertion de certitude anticipée. Un nouveau sophisme", in Écrits, du Seuil, Paris, 1966 [1945], pp.197-213.

11. Adriaensen, M., Over de subjectwording Een aantal representaties uit het onderwijs van Lacan, Idesça, Gent, 1992.

12. Blomme, D. and Hoens, D., "Subject en collectiviteit Een interperetatie van Lacans "Le temps logique", Psychoanalytische Perspectieven, Gent, 2002, pp.47-65.

13. Samuels, R., "Logical Times and Jouissance", Newsletter of the Freudian Field, vol.4, nr.1-2, 1990, pp.69-77.

14. Fink, B., "Logical Times and the Precipitation of Subjectivity", in Reading Seminars I and II: Lacan's Return to Freud, edited by Feldstein, R., Fink, B. and Jaanus, M., State University of New York, Albany, 1996, pp.356-386.

15. Lacan, J., Le Séminaire, Livre XI, Les quatre concepts fondamentaux de la psychanalyse. texte établi par J.-A. Miller, du Seuil, Paris, 1973 [1964].

16. Lacan, J. "Le stade du mirroir comme formateur de la fonction du Je", in Écrits, du Seuil, Paris, 1966 [1949], pp.93-100.

17. Lacan, J. "Le stade du mirroir comme formateur de la fonction du Je", in Écrits,, du Seuil, Paris, 1966 [1949], pp.93-100.

18. Lacan, J. "Fonction et champ de la parole et du langage en psychanalyse", in Écrits, du Seuil, Paris 1966 [1953], pp.237-322.

19. Povinelli, D.J. and Bering, J.M., "The Mentality of Apes Revisited”, Current Directions in Psychological Science, Vol.11, nr.4, 2002, pp.115-119.

20. Gallup, C.G. jr., “Chimpanzees: self-recognition.”, Science 169, 1970, pp.86-89.

21. Gallup, C.G. jr., "Self-recognition in primates: A comparative approach to the bidirectional properties of consciousness", American psychologist 32, 1977, pp.329-337.

22. Lacan, J. "Le stade du mirroir comme formateur de la fonction du Je", in Écrits,, du Seuil, Paris, 1966 [1949], pp.93-100.

23. Ramachrandran, V.S., "Mirror Neurons and imitation learning as the driving force behind "the great leap forward" in human evolution", 1999, unpublished, to be found on http://www.anticipation.info/texte/ramachandran/mirror_neurons_rama.html.

24. Umilta, M.A.; Kohler, E.; Gallese, V.; Fogassi, L.; Fadiga, L.; Keysers, C.; Rizzolatti, G. "I Know What You Are Doing: A Neurophysiological Study.”, Neuron 31., 2001, pp.155-165. 